\title{
Addressing Misconceptions in EFL Literature Learning Using Confidence Weighting Measures: Towards an EFL Literature Concept Inventory
}

\author{
Jackson Ver Steeg, Jr \\ Center for English Language Teaching, Wenzao Ursuline University of Languages 900 Mintsu $1^{\text {st }}$ Road, \\ Kaohsiung 807, Taiwan
}

*Corresponding Author: Jackson Ver Steeg, Jr, Center for English Language Teaching, Wenzao Ursuline University of Languages 900 Mintsu 1st Road, Kaohsiung 807, Taiwan

\begin{abstract}
Item-specific confidence weighting measures have been used previously to assess misconceptions in student learning of scientific theory in the form of concept inventories. These measures are usually used in a testing format, with students indicating not only their answer (as in a standard test), but indicating how confident they are in each answer. This allows the instructor to gauge how confidently they understand (or misunderstand) certain concepts. This paper takes that type of assessment measurement and applies it to a novel field, that of literature terms and concepts for students of English as a Foreign Language, by developing a unique two-dimensional implicit confidence measurement rubric. An analysis of student performance on a confidence weighted exam allows instructors to see in which specific areas student knowledge was clear or where misconceptions occurred and encourage the development of metacognition strategies by students.
\end{abstract}

Keywords: Confidence-Weighting, EFL Assessment, Literature Concept Inventory

\section{INTRODUCTION}

Recent work on the relative importance of schools, teachers, curricula, and student factors on learning have shown some interesting and surprising results. In terms of predicting student achievement, Marzano[1] indicated that only $7 \%$ of variance in achievement could be attributed to school effects (such as class size and curriculum) and $13 \%$ to teacher effects, while $80 \%$ of variance in achievement could be explained by student effects. Subsequent studies, as reported by Hattie [2] confirmed that over a broad range of studies the numbers may not be quite so extreme, but still student effects had the greatest effect. Among the strongest student effect is, not surprisingly, general cognitive ability. Among non-cognitive factors, however, Stankov[3]has reported that the best predictor of achievement in English and mathematics is student confidence, defined here simply as a level of certainty regarding the accuracy of one's answers.

Helping students gain such confidence can come through several means in the English language classroom. This paper introduces an assessment measure for teaching literature concepts in the EFL classroom that is designed to foster student confidence through provoking and emphasizing in test takers the metacognition that acts as a foundation for developing confidence in language usage. While concept inventories have been widely used in science education to develop metacognition, there isa distinct lack of such comprehensive concept inventories in either the humanities in general, EFL education, or literature education directed at EFL students.

\section{LiTERATURE REVIEW}

\subsection{Metacognition}

One primary method of developing a sense of confidence about one's knowledge is having knowledge of what one knows. Confidence, not surprisingly, is one aspect of what a number of researchers consider metacognitive awareness. The concept of metacognition, developed by John Flavell in the 1970s, has been applied to numerous fields of research. From metacognition, research has progressed to concepts of self-efficacy, arising from Bandura's work [4] and developed by Parajes [5]. Further 
work along a similar strain can be found in the concept of self-regulated learning, advanced primarily by the work of Zimmerman [6]. While these concepts overlap in some ways, confidence itself has been specifically identified as a better a better predictor than self-efficacy alone. In EFL learning, metacognition has been has been shown to be helpful in students managing their own learning strategies, and in studies such as Al-Makhalfi's[7], acts to guide student decisions regarding reading strategies adopted by the EFL learner, allowing them to monitor and direct their own learning.

\subsection{Confidence Weighting Measures}

One method to promote student reflection on their knowledge of taught material is the use of two dimensional confidence weighting testing methods, which incorporate not only the student's answer, but an indication of the level of certainty the student has regarding that answer. First developed by Ebel[8] and Soderquist[9], it was intended to reduce the importance of chance guessing by test respondents. There are two general forms of confidence weighting tests: explicit and implicit. In an implicit form, the students are given test questions that include a variable of certainty within the question format, and have been developed (Echternacht[10];Klymkowskyet al.[11])as a tool for recognizing student misconception for use in science education. In this implicit form, students could choose from several answers, but could also choose a lesser level of confidence by choosing "either A or B" or even "I don't know." Scoring varies, with higher points given for both correctness and confidence. That is, even "I don't know" may score higher than an incorrect answer. In the explicit form, students respond to a test question with both an answer and an indication of their confidence level. In terms of using confidence weighting as a method to promote metacognition in a test-taking format, Zoller et al. [12] concluded that such tests act to "engage students as partners in activities involving self-awareness and self-evaluation of their test performance and progress in learning" and "enhance their strengths and reduce their weaknesses, but also learn in greater depth and develop their higher-order cognitive skills-requiring capabilities."Numerous concept inventories have been developed for various scientific test batteries which promote metacognition, most notably those indicated in Table 1. There is, however, a distinct lack of such comprehensive concept inventories in either the humanities in general, EFL education, or literature education directed at EFL students.

Table1. Science Concept Inventories

\begin{tabular}{|l|l|}
\hline Assessment & Developers \\
\hline Force Concept Inventory & Hestenes, D., Wells, M., \&Swackhamer, G. [13]. \\
\hline Force and Motion Concept Evaluation & Thornton, R. K., \& Sokoloff, D. R. [14]. \\
\hline Natural Selection Concept Inventory & Anderson, D. L., Fisher, K. M., \& Norman, G. J. [15]. \\
\hline Quantum Mechanics Concept Survey & McKagan, S.B., \&Wieman, C.E. [16]. \\
\hline Brief Electricity and Magnetism Assessment & Ding, L., Chabay, R., Sherwood, B., \&Beichner, R. [17]. \\
\hline
\end{tabular}

In the test developed here for EFL students of literature, students are asked to not only indicate their confidence, but to do so relative to other questions on the exam. This is done by means of a budget, where students have a limited number of points to allocate among test questions in a certain section of the exam. This formulation, here termed a "budget," was used by Jack et al.[18] as Total Point Value (TPV) in science education testing. They noted two advantages of such a restriction:"First, this restriction prevents a respondent from weighting all responses with a high weighted value on the chance of being a lucky guesser. Second, this restriction encourages the respondent to differentiate levels of confidence toward their feeling of knowing among answer selections." Thereby, students must determine where their highest confidence lies in the process of testing itself. Through this process, students participate in the metacognitive process.

\subsection{Literature Concept Testing}

Carter and Long [19] describe two different examination types for use in literature testing for EFL students, those of conventional and language-based approaches, each of which they separate into three question types. The conventional approach is composed of paraphrase and context questions, describe and discuss questions and evaluate and criticize questions. According to Carter and Long, they pose disadvantages in the EFL classroom, mainly that candidates are rarely asked to read closely and can answer even if they have read only a translation or simplified version of the text. They therefore suggest using a language-based approach that emphasizes the "centrality of language to the 
Addressing Misconceptions in EFL Literature Learning Using Confidence Weighting Measures: Towards an EFL Literature Concept Inventory

medium of literature." The question types are general comprehension, text focus, and personal response and impact questions. These are summarized in Table 2.

Table2. Conventional and Language-based test formats, from Carter \& Long [19]

\begin{tabular}{|l|l|l|l|l|}
\hline Approach & & Question Type & Essential Element & Focus \\
\hline Conventional & I & paraphrase and context & text extracts & text significance \\
\cline { 2 - 5 } & II & describe and discuss & $\begin{array}{l}\text { retrieval } \\
\text { information from text }\end{array}$ & \\
\cline { 2 - 5 } & III & evaluate and criticize & evaluation of writing & plot and character \\
\hline \multirow{2}{*}{$\begin{array}{l}\text { Language- } \\
\text { based }\end{array}$} & I & general comprehension & reference text & general situation or themes \\
\cline { 2 - 5 } & II & text focus & inferences & \\
\cline { 2 - 5 } & III & personal response and impact & $\begin{array}{l}\text { connections between } \\
\text { text and world }\end{array}$ & \\
\hline
\end{tabular}

Absent from these approaches, however, are a few elements of importance. First, there is no distinct vocabulary category that tests the vocabulary in the text. Second, the language-based focus, while successfully engaging students in discussions of the text in the classroom, fails to give sufficient attention to literary conventions and textual structure that underpins literature texts. That is, while the language-based approach helps students engage with the text, it often does so at the exclusion of identifying literary features and structure that encompass a more complete understanding of literature. Literature tests should in fact test fundamentals of literature. Third, absent from these testing approaches is an element of metacognition.

The test format offered here is designed to incorporate such an element of metacognition into literature testing in the EFL classroom, and can include both structural and language-based teaching approaches. This inclusion of self-awareness may have the benefit of enhancing student strengths, reducing weaknesses, and developing higher-order thinking skills, as suggested by Zoller et al. [12].

\section{TEST FORMAT AND METHODS}

Though previously used for science and math education and the testing of proper understanding of scientific concepts, this paper expands this method of testing to the humanities and the understanding of literature concepts. Whereas in a physics test battery, there is a definite correct response, some may question the applicability to literature, where answers are often not as definite. A literature text, however, is a closed system - a text that contains its meaning within itself, or as H. G. Widdowson has noted, "since there is no access to the physical world outside the text, ...each line is meant to interrelate with the others to create an internally coherent meaning...we negotiate meaning and set about making sense of expressions by referring them to the other parts of the text (discourse) in which they occur" [20]. With test questions limited to the text being studied and careful question construction that allows for multiple supportable interpretations, testing of literary concept knowledge can be accurately tested. For example, instead of asking a question such as "What is Oedipus' tragic flaw?" (a question that has been debated for centuries), it might be rephrased as "Which of the following best supports the idea of hubris as Oedipus' tragic flaw?"

\subsection{Test Subjects}

Students assessed were drawn from several college introductory literature classes in a language college in Taiwan. For most, this was one of their first courses in English literature and the presentation of literature concepts. The confidence weighting tests were given as their midterm and final exams. The first semester dealt with short stories and poetry, while the second addressed drama. The example questions in the appendix where constructed to test student knowledge of three texts: Susan Glaspell's Trifles, Henrik Ibsen's The Dollhouse, and Sophocles' Oedipus Rex.

\subsection{Test Question Weighting}

In an introduction to the test format, students were instructed to complete each test section, and then assign a high, middle, or low confidence point value to each question item in the section by filling in a circle representing their point value choice. The sum of these points must equal the total value for each section. That is, they must spend their entire budget, but no more or no less. Students easily understood the nature of the weighting rules by noting that since there were only three confidence 
levels, with the average point value for the section being the middle confidence value, any choice increasing confidence level for one questions must be accompanied by a decrease in another question. (Additionally, since each section contains 10 questions, the number of increases could be easily calculated on the fingers of one hand, while decreases could be counted on the fingers of the other!) Due to the construction of the test, discussed below, confidence values could be relatively easily assigned.

\subsection{Test Construction}

In this format designed for EFL students, both language learning and literature concepts are tested. The test is divided into four sections, all of which have 10 questions. Section 1 tests vocabulary only. Section 2 tests level one analysis of dialogue context and characterization, asking students to match spoken dialogue to the character which said it or who is referred to in it. This second section also verifies that students can identify the most important dialogue in the text in English. These two sections are worth $20 \%$ each, or 20 points each.

Table3. Examination Section Breakdown

\begin{tabular}{|l|l|l|l|l|l|}
\hline Section & Questions & Total Points & Possible Weights & Question types & \multicolumn{1}{|c|}{ Concepts } \\
\hline 1 & \multirow{2}{*}{10} & 20 (avg. 2) & $\begin{array}{l}\text { (4) } 3 \\
\text { (4) } 2 \\
\text { (4) } 1\end{array}$ & matching, cloze & vocabulary \\
\hline 2 & 10 & 20 (avg. 2) & $\begin{array}{l}\text { (4) } 3 \\
\text { (4) } 2 \\
\text { (4) } 1\end{array}$ & matching & $\begin{array}{l}\text { character } \\
\text { dialogue context }\end{array}$ \\
\hline 3 & 10 & 30 (avg. 3) & $\begin{array}{l}\text { (4) } 3 \\
\text { (4) } 2\end{array}$ & $\begin{array}{l}\text { multiple choice, } \\
\text { true/false }\end{array}$ & $\begin{array}{l}\text { literature concepts, textual } \\
\text { knowledge } \\
\text { interpretation, } \\
\text { characterization, narrative } \\
\text { structure, plot, theme }\end{array}$ \\
\hline 4
\end{tabular}

The next two sections, with $30 \%$ or 30 points each, deal with more difficult analysis questions, focusing on structure, theme, interpretation, and application of literature terms.

\subsection{Question Construction}

The test questions were categorized both by question type and by concept(s) being tested. Question types were vocabulary matching and cloze, dialogue matching, multiple choice, passage analysis, and true/false. For simplicity, however, only the concept categories are discussed here. The primary concepts taught and tested were knowledge of: setting, structure, plot, characterization, theme, text inferences, literary terms/concepts, passage interpretation, dialogue context, and vocabulary. An analysis of student responses to questions identified by these codes in the two-dimensional implicit confidence weighted exam can indicate the confidence level that students had about different literature concepts that they had learned, giving solid quantitative feedback to the instructor on how well the material was learned by the students, and if any notable misconceptions have occurred. In addition, students can benefit by identifying which conceptual understandings are lacking.

The test uses item-specific indications of confidence rather than general in order to provide feedback to instructors on the areas where student on the whole lack confidence in the taught material.Test items were categorized in an inventory format based on literature conventions and test questions were coded with a primary and sometimes a secondary concept code. Since much EFL literature teaching seems to utilize short stories as texts, this inventory has been specifically developed for fiction,but can be applied to drama as well. An additional section could be easily added to test knowledge of poetry conventions. Note that not all subheadings have a specific code. More important concepts central to literature learning, such as symbolism or irony, could be specifically coded by the instructor if deemed necessary. These codes denoting specific concepts were not included on the student examination so as not to overwhelm them. They could be reserved for instructor use only, or could be introduced when the examination is reviewed in order to help students specifically target areas necessary for improvement. 
Addressing Misconceptions in EFL Literature Learning Using Confidence Weighting Measures: Towards an EFL Literature Concept Inventory

Table4. Partial EFL Literature Concept Inventory

\begin{tabular}{|c|c|c|c|}
\hline & Concept Tested & Code & Appendix A Sample Item \\
\hline 1. & Elements of Fiction/Drama & & \\
\hline a. & Setting & SET & 31 \\
\hline$i$. & time & & \\
\hline$i$. & place & & 31 \\
\hline$i$. & situation & & 31 \\
\hline $\mathrm{b}$. & Structure & STR & 33 \\
\hline$i$. & exposition & & \\
\hline i. & conflict & & \\
\hline$i$. & rising/falling action & & \\
\hline . & causal interconnectedness & & \\
\hline . & crisis & & \\
\hline$i$. & climax & & 36 \\
\hline$i$. & resolution & & \\
\hline c. & plot & PLT & \\
\hline d. & characterization & CHR & 24 \\
\hline e. & theme & THM & 36 \\
\hline 2. & Inferences & INF & 32,36 \\
\hline 3. & Literature terms/concepts & TRM & 23,34 \\
\hline a. & figurative language & & \\
\hline b. & symbolism & SYM & 21 \\
\hline c. & irony & & \\
\hline 4. & Passage Interpretation & INT & 22,35 \\
\hline 5. & Dialogue context & DIA & 11 \\
\hline 6. & Vocabulary & VOC & $1,2,3$ \\
\hline
\end{tabular}

Questions can be then placed in test sections, vocabulary in Section 1, dialogue context in Section 2 , and others in Sections 3 and 4. Examples can be found in Appendix A.

\subsection{Question Scoring}

First, sections totals are verified to ensure that students had followed directions and budgeted their points within each section correctly (20 total points in Sections 1 and 2; 30 total points in Sections 3 and 4). Next correct responses are scored and totaled. In addition, there are six possible response categories that help to gauge true student understanding of literature concepts, based on the combination of correctness and item confidence. These are shown in Table 5. These responses can help identify the student's knowledge as well as their own metacognition for each item. C3 identifies the desired response that a student has correctly identified both the answer, and the fact that they know that they can identify the correct answer. C1 and I1 are fairly indistinguishable. Being at low confidence, they are simple lucky or unlucky guesses. I3, however, identifies the area of greatest concern, where students believe that they understand a particular concept, when in fact they do not.

Table5. Scoring

\begin{tabular}{|l|l|l|}
\hline Response Code & \multicolumn{1}{|c|}{ Feature } & \multicolumn{1}{|c|}{ Interpretation } \\
\hline C3 & correct answer + high confidence in answer & $\begin{array}{l}\text { student understands concept clearly and } \\
\text { knows that he/she knows }\end{array}$ \\
\hline C2 & correct answer + medium confidence in answer & $\begin{array}{l}\text { student understands concept with only } \\
\text { some confidence }\end{array}$ \\
\hline C1 & correct answer + low confidence in answer & a correct ("lucky") guess \\
\hline I1 & incorrect answer + low confidence in answer & an incorrect ("unlucky") guess \\
\hline I2 & $\begin{array}{l}\text { incorrect answer + medium confidence in } \\
\text { answer student misunderstands concept, with } \\
\text { some doubt about ability to answer }\end{array}$ \\
\hline I3 & incorrect answer + high confidence in answer & $\begin{array}{l}\text { Student has a misconception. } \\
\text { Mistakenly believes he/she is correct. }\end{array}$ \\
\hline
\end{tabular}

\subsection{Test Review}

During the test review, as correct answers are explained to students, the relative confidence with which they answered test items becomes quite clear to them as they are in fact forced into considering 
their own metacognition in the area of literature study. As noted, the instructor could, if deemed helpful, include the question coding or simply mention the area tested so that students could see the overall picture of where their own knowledge and knowledge of that knowledge exists. For example, a student might observe that they answered incorrectly at low or medium confidence for several setting (SET) questions. This would suggest that that student pay more attention to the setting of the text in future study. A student might also observe that they answered incorrectly at high confidence several dialogue (DIA) questions attributable to a particular character, or perhaps a literature concept such as irony. This should suggest to the student that she did not, in fact, fully understand that character, or the concept of irony. The student would then be encouraged to reflect on why that misconception occurred.

\section{RESUltS AND DisCUSSION}

For most students assessed by this method, this was one of their first courses in English literature and the presentation of literature concepts. The confidence weighting tests were given as their midterm and final exams. Student reactions to this exam format were preliminarily measured by a post-test questionnaire. Items were ranked on a 5-point Likert scale, with 1 being "strongly disagree" and 5 representing "strongly agree." Mean scores are shown in Table 3. These results from questions 1-3 and 7 suggest a few things. First, overall students felt that the confidence-weighting format helped them become more aware of their metacognition in the area of literature study and how they could improve. That that knowledge resulted in an immediate improvement in confidence was not as clear. That is probably to be expected. Testing is seldom seen by students as anything other than stressful. An additional questionnaire given at a later time might indicate the overall confidence-building effect after a period of reflection. Regarding the format of the test, responses to questions 4-6 indicated that the format was understandable and some students found it to be enjoyable. Lastly, questions 8-10 dealing with metacognition provided a picture of the current amount of self-reflection that students currently incorporate into their learning patterns. The responses suggest that though they may abstractly think about their learning, the students overall did not actively plan and organize their learning. This indicates that metacognitive practices in general are not being actively embraced by either teachers or students in the EFL classroom, and that there is sufficient need for a type of test such as this that incorporates an element of metacognition. In addition, many students felt that the test format was fun and, as evidenced by open-ended comments, was a welcome change from standard formats.

Table6. Questionnaire Results

\begin{tabular}{|c|c|c|}
\hline & & $\begin{array}{l}\text { Mean Score } \quad(1=\text { Strongly } \\
\text { Disagree, } 5=\text { Strongly Agree })\end{array}$ \\
\hline & \multicolumn{2}{|l|}{ The format of the test... } \\
\hline 1 & ...made me think about how well I knew the material. & $4.05(n=113)$ \\
\hline 2 & ...gave me confidence & $3.79(n=113)$ \\
\hline \multirow[t]{2}{*}{3} & ...helped me understand how I can improve & $4.07(n=113)$ \\
\hline & \multicolumn{2}{|l|}{ Answering questions in this format was... } \\
\hline 4 & ...difficult & $3.00(n=55)$ \\
\hline 5 & ...fun & $3.48(n=55)$ \\
\hline 6 & ...confusing & $2.87(n=55)$ \\
\hline \multirow[t]{2}{*}{7} & ...confidence-building & $3.54(n=55)$ \\
\hline & \multicolumn{2}{|l|}{ Normally, ... } \\
\hline 8 & I reflect on what I am learning. & $3.65(n=55)$ \\
\hline 9 & I organize my learning well. & $3.37(n=55)$ \\
\hline 10 & I review my learning regularly. & $3.35(n=55)$ \\
\hline 11 & I do not take many risks. & $3.02(n=55)$ \\
\hline
\end{tabular}

An additional comments section provided various responses, most of which were positive. The positive comments included: "It was wonderful!" and "I really enjoy this new style exam"

Numerous comments noted the advantage of being able to improve your score with the test format: "I think it is a good way for me to let those questions I know the answers to get higher points"; "it is good for me to get much more score than before." An examination of raw and adjusted scores shows 

an EFL Literature Concept Inventory

that nearly all students show an increase in score after using weighting procedures. Most earn an increase of 3-8\% on the test due to the test format.

Several students noted the metacognitive elements of the test: "The test showed me vocabularyis a huge weakness of my study"; "I think it is quite fun to take an exam like this. In this way, I weight the questions; I also learn which parts I should put more efforts (sic)"

The negative comments included mostly comments about concerns with math and with the difficulty of deciding:

"I think it's difficult when I have to decide how many points I should give to the questions that I am not sure. But it is an interesting way of testing I've never had before."

"It's difficult for me to give points in each questions." part."

"It's good for me to control the score, but it's too tired (sic) to count the total score for each

It should be noted that in earlier forms of this test, students were instructed that if they did not correctly total their score, they would receive zero points for the section. This seemed to cause a lot of anxiety. The instructions were then revised such that students were told that if they did not correctly add the points for a section, all questions in that section would receive an average valuethereby defeating any advantage (extra points) gained by adjusting point value. This seemed to eliminate most of the anxiety felt by students regarding totaling the points for each section.

Some of the strongest negative comments come from students who are confident in many of their answers and are reluctant or disappointed to be forced to choose a low-confidence value for an answer that they are confident of. As one student noted, "Sometimes I think most of answers are correct, but I still have to make total equal 20. Therefore, I need to some weight at 1 score even though I think the answer is right." This comment reflects that fact that the students who are most confident in their answers throughout all sections will tend to choose the average value for all questions. Conversely, there are students who indicate trouble choosing anything above low confidence and are faced with indicating a mid-level confidence for all. This emphasizes that the most important factors regarding scoring in the exam are found at the extremes of C3 and I3. Because C2 and I2 categories may be chosen by students who have both a lot of or very little confidence in their answers, it is difficult to make suppositions on all respondents who answer primarily with the mean value. On an individual level, however, students should recognize their own strategies regarding using the mean value for each item, which confirms the metacognitive value of this exam format.

\section{CONCLUSION}

Further research into this test format will include a more thorough and detailed analysis of which types of questions are most frequently understood with confidence as well as which are terms and concepts are most readily misunderstood. In addition, further research will investigate whether natural proclivities toward risk-taking determine the effectiveness of this item-specific two dimensional test format. Additional research on format, specifically developing a computer-based exam, would vastly simplify the test. Students would not have to worry about miscounting assigned confidence weight values and would better visualize the effect of changing confidence levels. Currently, the author is unaware of a specific online format that achieves this goal at low cost and with ease of use.

The longer term effect of this type of confidence-weighting test is to call student's attention to their own metacognition. Once students can see the value of reflecting on what they do or do not know, then can work to develop studying and learning methods that include active reflection on their progress in learning taught material. This form of confidence weighting test can provide both the teacher and students with an objective measure of performance and learning progress. Correct responses tied with confident responses builds student confidence. Conversely, student analysis of levels of confidence assigned to incorrect responses gives both students and teachers the role of "partners" in determining reasons for misconceptions and how to best ameliorate those misconceptions. 


\section{ACKNOWLEDGEMENTS}

The author wishes to thank Brady Jack at National Sun Yat-sen University, Taiwan for his guidance and encouragement.

This research did not receive any specific grant from funding agencies in the public, commercial, or not-for-profit sectors.

\section{REFERENCES}

[1] Marzano, R. J. A quantitative synthesis of research on school-level, teacher-level, and student-level variables related to academic achievement. Aurora, CO: Mid-continent Research for Education and Learning, (2000).

[2] Hattie, J. A. Visible learning: A synthesis of 800+ meta-analyses on achievement. Abingdon: Routledge, (2009).

[3] Stankov, L., Lee, J., Luo, W., \& Hogan, D. J. Confidence: A better predictor of academic achievement than self-efficacy, self-concept and anxiety? Learning and Individual Differences, (2012).

[4] Bandura, A. The explanatory and predictive scope of self-efficacy theory. Journal of social and clinical psychology, 4(3), 359-37, (1986).

[5] Pajares, F. Self-efficacy beliefs in academic settings. Review of educational research, 66(4), 543-578, (1996).

[6] Zimmerman, B. J. Becoming a self-regulated learner: An overview. Theory into practice, 41(2), 64-70, (2002).

[7] Al-Mekhlafi, A. M. EFL Learners' Metacognitive Awareness of Reading Strategies. International Journal of Instruction, 11(2), 297-308.(2018)

[8] Ebel, R. L. Confidence weighting and test reliability. Journal of Educational Measurement, 2(1), 49-57, (1965).

[9] Soderquist, H. O. A new method of weighting scores in a true-false test. The Journal of Educational Research, 30(4), 290-292, (1936).

[10] Echternacht, G. J. The use of confidence testing in objective tests. Review of Educational Research, 42(2), 217-236, (1972).

[11] Klymkowsky, M. W., Taylor, L. B., Spindler, S. R., \& Garvin-Doxas, R. K. Two-dimensional, implicit confidence tests as a tool for recognizing student misconceptions. Journal of College Science Teaching, 36(3), 44, (2006).

[12] Zoller, U., Fastow, M., Lubezky, A. \&Tsaparlis, G. Students' self-assessment in chemistry examinations requiring higher-and lower-order cognitive skills. Journal of Chemical Education 76, 112-113, (1999).

[13] Hestenes, D., Wells, M., \& Swackhamer, G. Force concept inventory. The physics teacher, 30(3), 141-158, (1992).

[14] Thornton, R. K., \& Sokoloff, D. R. Assessing student learning of Newton's laws: The force and motion conceptual evaluation and the evaluation of active learning laboratory and lecture curricula. American Journal of Physics, 66, 338, (1998).

[15] Anderson, D. L., Fisher, K. M., \& Norman, G. J. Development and evaluation of the conceptual inventory of natural selection. Journal of research in science teaching, 39(10), 952-978, (2002).

[16] McKagan, S.B., \& Wieman, C.E. Exploring student understanding of energy through the quantum mechanics concept survey. AIP Conference Proceedings 818: 65-68, (2005).

[17] Ding, L., Chabay, R., Sherwood, B., \& Beichner, R. Evaluating an electricity and magnetism assessment tool: Brief electricity and magnetism assessment. Physical review special Topics-Physics education research, 2(1), 010105, (2006).

[18] Jack, B. M., Liu, C. J., Chiu, H. L., \& Tsai, C. Y. Measuring the confidence of $8^{\text {th }}$ grade Taiwanese students' knowledge of acids and bases. International Journal of Science and Mathematics Education, 10(4), 889-905, (2012).

[19] Carter, R., \& Long, M. N. Testing literature in EFL classes: Tradition and innovation. ELT Journal, 44(3), 215-221, (1990).

[20] Gajdusek, L. Toward wider use of literature in ESL: Why and how. Tesol Quarterly, 22(2), 227-257, (1988).

\section{Appendix A Sample Questions}

Instructions: There are 4 parts in the exam. Parts A \& B are worth 20 points each, and Parts C \& D are worth 30 points each. After you select your answer for each question, you need to weight how many points you feel your answer is worth. The total number of wagers from the following 10 questions MUST equal exactly 20 points for $\mathrm{A} \& \mathrm{~B}$, and 30 points for $\mathrm{C} \& \mathrm{D}$. 
Addressing Misconceptions in EFL Literature Learning Using Confidence Weighting Measures: Towards an EFL Literature Concept Inventory

Weighting method for each question:

\begin{tabular}{|c|c|c|}
\hline & Parts A \& B & Parts C \& D \\
\hline $\begin{array}{l}\text { If you are LESS sure if an answer is correct, write the lowest value in the } \\
\text { box to the right of the answers. }\end{array}$ & $\begin{array}{l}\text { (4) } 3 \\
\text { (4) } 2 \\
\text { (4) } 1\end{array}$ & $\begin{array}{l}\text { (4) } 4 \\
\text { (4) } 3 \\
\text { (4) } 2\end{array}$ \\
\hline $\begin{array}{l}\text { If you are SOMEWHAT sure an answer is correct, write the middle value } \\
\text { in the box. }\end{array}$ & $\begin{array}{l}\text { (4) } 3 \\
\text { (4) } 2 \\
\text { (4) } 1\end{array}$ & $\begin{array}{l}\text { (4) } 4 \\
\text { (4) } 3 \\
\text { (4) } 2\end{array}$ \\
\hline $\begin{array}{l}\text { If you are MORE sure an answer is correct, write the highest value in the } \\
\text { box. }\end{array}$ & $\begin{array}{l}\text { (4) } 3 \\
\text { (4) } 2 \\
\text { (4) } 1\end{array}$ & $\begin{array}{l}\text { (4) } 4 \\
\text { (4) } 3 \\
\text { (4) } 2\end{array}$ \\
\hline $\begin{array}{l}\text { If you are equally sure of ALL of your answers, write the middle value in } \\
\text { all boxes. }\end{array}$ & $\begin{array}{l}\text { (4) } 3 \\
\text { (4) } 2 \\
\text { (4) } 1\end{array}$ & $\begin{array}{l}\text { (4) } 4 \\
\text { (4) } 3 \\
\text { (4) } 2\end{array}$ \\
\hline
\end{tabular}

Make Sure that the Total for Each Part Matches the Total Points

\section{Part A: 20 Points}

\begin{tabular}{|c|c|c|c|c|c|c|}
\hline \# & \multicolumn{2}{|l|}{ Question } & \multicolumn{2}{|r|}{$\begin{array}{l}\text { Weight }(\mathrm{mu} \\
\text { st equal } 20)\end{array}$} & Score & Code \\
\hline \multicolumn{7}{|c|}{$\begin{array}{l}\text { Vocabulary } \\
\text { Use these wo }\end{array}$} \\
\hline \multicolumn{2}{|c|}{$\begin{array}{l}\text { A.abandoned } \\
\text { B.wring } \\
\text { C.squander } \\
\text { D.motive }\end{array}$} & $\begin{array}{l}\text { E.recuperate } \\
\text { F.droop } \\
\text { G.went to pieces } \\
\text { H. exhilarated }\end{array}$ & \multicolumn{4}{|c|}{$\begin{array}{l}\text { I.detour } \\
\text { J.postpone } \\
\text { K. hypocrite } \\
\text { L. trifles }\end{array}$} \\
\hline 1 & \multicolumn{3}{|c|}{ to bend or hang downward } & $\begin{array}{l}\text { (4) } 3 \\
\text { (4) } 2 \\
\text { (4) } 1\end{array}$ & & $\begin{array}{ll}\mathrm{C} 3 & \mathrm{I} 3 \\
\mathrm{C} 2 & \mathrm{I} 2 \\
\mathrm{C} 1 & \mathrm{I} 1\end{array}$ \\
\hline 2 & \multicolumn{3}{|c|}{ to waste, especially time, money or opportunity } & $\begin{array}{l}\text { (4) } 3 \\
\text { (4) } 2 \\
\text { (4) } 1\end{array}$ & & $\begin{array}{ll}\mathrm{C} 3 & \mathrm{I} 3 \\
\mathrm{C} 2 & \mathrm{I} 2 \\
\mathrm{C} 1 & \mathrm{I} 1 \\
\end{array}$ \\
\hline 3 & \multicolumn{3}{|c|}{$\begin{array}{l}\text { No one lives in that house — it has been __ for at least ten } \\
\text { years. }\end{array}$} & $\begin{array}{l}\text { (4) } 3 \\
\text { (4) } 2 \\
\text { (4) } 1\end{array}$ & & $\begin{array}{ll}\text { C3 } & \text { I3 } \\
\text { C2 } & \text { I2 } \\
\text { C1 } & \text { I1 }\end{array}$ \\
\hline
\end{tabular}

Part B: 20 Points

\begin{tabular}{|c|c|c|c|c|c|c|}
\hline$\#$ & \multicolumn{2}{|l|}{ Question } & Answer & $\begin{array}{l}\text { Weight(must } \\
\text { equal 20) }\end{array}$ & Score & Code \\
\hline \multicolumn{7}{|c|}{$\begin{array}{l}\text { Who says the following lines? } \\
\text { Use these characters to answer questions 11-20: }\end{array}$} \\
\hline \multicolumn{2}{|c|}{$\begin{array}{l}\text { A. Mrs. Peters } \\
\text { B. Sheriff Peters } \\
\text { C. County Attorney George } \\
\text { Henderson } \\
\text { D. Mrs. Hale }\end{array}$} & $\begin{array}{l}\text { E. Mr. Hale } \\
\text { F. Mrs. Wright } \\
\text { G. Nora } \\
\text { H. Torvald }\end{array}$ & \multicolumn{4}{|c|}{$\begin{array}{l}\text { I. Mrs. Linde } \\
\text { J. Dr. Rank } \\
\text { K. Krogstad } \\
\text { L. None of the above }\end{array}$} \\
\hline 11 & \multicolumn{2}{|c|}{$\begin{array}{l}\text { "No, Wright wouldn't like the bird-a thing that sang. } \\
\text { She used to sing." }\end{array}$} & & $\begin{array}{l}\text { (4) } 3 \\
\text { (4) } 2 \\
\text { (4) } 1\end{array}$ & & $\begin{array}{ll}\text { C3 } & \text { I3 } \\
\text { C2 } & \text { I2 } \\
\text { C1 } & \text { I1 }\end{array}$ \\
\hline
\end{tabular}

\section{Part C: 30 Points}

\begin{tabular}{|c|c|c|c|}
\hline 21 & $\begin{array}{l}\text { In "Trifles," the birdcage is most likely symbolic of: } \\
\begin{array}{ll}\text { A. The Wrights' marriage } & \text { B. Mrs. Wright } \\
\text { C. The death of Mr. Wright } & \text { D. The preserves }\end{array}\end{array}$ & $\begin{array}{l}\text { (4) } 4 \\
\text { (4) } 3 \\
\text { (4) } 2 \\
\end{array}$ & $\begin{array}{ll}\text { C3 } & \text { I3 } \\
\text { C2 } & \text { I2 } \\
\text { C1 } 1 & \text { I1 } \\
\end{array}$ \\
\hline 22 & $\begin{array}{l}\text { What does Mrs. Linde mean when she says "Not even a sense of loss to } \\
\text { feed on-“? } \\
\text { A. It happened too long ago to be sad about. } \\
\text { B. She didn't love her husband, so she felt no sadness. } \\
\text { C. She fell apart when she lost her husband. } \\
\text { D. She didn't have any children in her marriage. }\end{array}$ & $\begin{array}{l}\text { (4) } 4 \\
\text { (4) } 3 \\
\text { (4) } 2\end{array}$ & $\begin{array}{ll}\text { C3 } & \text { I3 } \\
\text { C2 } & \text { I2 } \\
\text { C1 } & \text { I1 }\end{array}$ \\
\hline
\end{tabular}


Addressing Misconceptions in EFL Literature Learning Using Confidence Weighting Measures: Towards an EFL Literature Concept Inventory

\begin{tabular}{|c|c|c|c|c|}
\hline 23 & $\begin{array}{l}\text { Which of these does NOT describe a foil character? } \\
\text { A. is usually a main character } \\
\text { B. is usually a minor character } \\
\text { C. provides contrast with another character } \\
\text { D. has something similar in situation as another character }\end{array}$ & & \begin{tabular}{|l} 
(4) 4 \\
(4) 3 \\
(4) 2
\end{tabular} & $\begin{array}{lll}\mathrm{C} 3 & \mathrm{I} 3 \\
\mathrm{C} 2 & \mathrm{I} 2 \\
\mathrm{C} 1 & \mathrm{I} 1\end{array}$ \\
\hline 24 & $\begin{array}{l}\text { Which is not one of Nora's deceptions? } \\
\text { A. she says that Kristine bought the macaroons } \\
\text { B. she didn't really make Christmas decorations } \\
\text { C. she changes her story when she is talking with Mrs. Linde } \\
\text { D. she tells Helmer that Dr. Rank loaned her the money, when it was } \\
\text { really Krogstad. } \\
\text { E. they are all examples of Nora's deceptions }\end{array}$ & & $\begin{array}{l}\text { (4) } 4 \\
\text { (4) } 3 \\
\text { (4) } 2\end{array}$ & $\begin{array}{ll}\mathrm{C} 3 & \mathrm{I} 3 \\
\mathrm{C} 2 & \mathrm{I} 2 \\
\mathrm{C} 1 & \mathrm{I} 1\end{array}$ \\
\hline 25 & $\begin{array}{l}\text { What is the main setting ofOedipus Rex? } \\
\text { A. Cithaeron, during a Sphinx scare } \\
\text { B. Athens, during a plague } \\
\text { C. Corinth, during a plague } \\
\text { D. Thebes, during a plague }\end{array}$ & & $\begin{array}{l}\text { (4) } 4 \\
\text { (4) } 3 \\
\text { (4) } 2\end{array}$ & $\begin{array}{lll}\text { C3 } & \text { I3 } \\
\text { C2 } & \text { I2 } \\
\text { C1 } & \text { I1 }\end{array}$ \\
\hline 26 & $\begin{array}{l}\text { If you are watching a performance of } A \text { Doll's House, and two women } \\
\text { were having a conversation on stage, you could infer who is Mrs. Linde } \\
\text { by... } \\
\text { A. ... her crying when talking about her husband } \\
\text { B. ...the fact that she is acting more childish } \\
\text { C. ...her more conservative clothing } \\
\text { D. ...the fact that she kisses Krogstad when she sees him for the first } \\
\text { time }\end{array}$ & & $\begin{array}{l}\text { (4) } 4 \\
\text { (4) } 3 \\
\text { (4) } 2\end{array}$ & $\begin{array}{ll}\mathrm{C} 3 & \mathrm{I} 3 \\
\mathrm{C} 2 & \mathrm{I} 2 \\
\mathrm{C} 1 & \mathrm{I} 1\end{array}$ \\
\hline 27 & $\begin{array}{l}\text { Which one is NOT true about the structure of Oedipus Rex? } \\
\text { A. The Parados is the entrance of the chorus. } \\
\text { B. A major character sings/chants the odes. } \\
\text { C. The strophe and antistrophe refer to the movements of the chorus. } \\
\text { D. The odes come after the scenes (Ode } 3 \text { after Scene } 3 \text {, Ode } 2 \text { after } \\
\text { Scene 2, etc.) }\end{array}$ & & $\begin{array}{l}\text { (4) } 4 \\
\text { (4) } 3 \\
\text { (4) } 2\end{array}$ & $\begin{array}{lll}\mathrm{C} 3 & \mathrm{I} 3 \\
\mathrm{C} 2 & \mathrm{I} 2 \\
\mathrm{C} 1 & \mathrm{I} 1\end{array}$ \\
\hline 28 & $\begin{array}{l}\text { Which one of these would NOT break the fourth wall on the stage? } \\
\text { A. a sign on a chair that reads "Oedipus' throne" } \\
\text { B. at the end of Shakespeare's The Tempest, when the character } \\
\text { Prospero asks for the audience to applaud in order that he can sail home. } \\
\text { C. an actor facing in the direction of the audience, but not looking at } \\
\text { them, when another character is speaking } \\
\text { D. scary music played during a tense scene }\end{array}$ & & $\begin{array}{l}\text { (4) } 4 \\
\text { (4) } 3 \\
\text { (4) } 2\end{array}$ & $\begin{array}{ll}\mathrm{C} 3 & \mathrm{I} 3 \\
\mathrm{C} 2 & \mathrm{I} 2 \\
\mathrm{C} 1 & \mathrm{I} 1\end{array}$ \\
\hline 29 & $\begin{array}{l}\text { What is a good interpretation of this passage?: "And then I killed them } \\
\text { all. If it happened there was any tie of kinship twixt this man and Laius, } \\
\text { what man on earth [is] so hated by the Gods?" } \\
\text { A. He feels bad at having killed his father. } \\
\text { B. He feels bad at having killed an innocent man. } \\
\text { C. He feels bad at having killed the king. } \\
\text { D. He feels bad about not listening to the oracle. }\end{array}$ & & $\begin{array}{l}\text { (4) } 4 \\
\text { (4) } 3 \\
\text { (4) } 2\end{array}$ & $\begin{array}{ll}\text { C3 } & \text { I3 } \\
\text { C2 } & \text { I2 } \\
\text { C1 } & \text { I1 }\end{array}$ \\
\hline 30 & $\begin{array}{l}\text { One likelyreason for Oedipus blinding himself is that... } \\
\text { A. it is symbolic of the idea that there is some knowledge that is too } \\
\text { much to bear } \\
\text { B. he doesn't want to see Jocasta again. } \\
\text { C. it was part of the oracle's prophecy } \\
\text { D. he wants to have the same gift as Teiresias }\end{array}$ & & $\begin{array}{l}\text { (4) } 4 \\
\text { (4) } 3 \\
\text { (4) } 2\end{array}$ & $\begin{array}{ll}\text { C3 } & \text { I3 } \\
\text { C2 } & \text { I2 } \\
\text { C1 } & \text { I1 }\end{array}$ \\
\hline \multicolumn{2}{|c|}{30 points? $\Rightarrow$} & TOTAL $=$ & & \\
\hline
\end{tabular}

Appendix B Student Questionnaire

\begin{tabular}{|l|l|l|l|l|l|l|}
\hline & & Strongly Disagree & Disagree & Neutral & Agree & Strongly Agree \\
\hline & 1 & 2 & 3 & 4 & 5 \\
\hline & $\begin{array}{l}\text { The format of the test... } \\
\text {...made me think about how } \\
\text { well I knew the material. }\end{array}$ & 1 & 2 & 3 & 4 & 5 \\
\hline 2 & $\ldots$...gave me confidence & 1 & 2 & 3 & 4 & 5 \\
\hline
\end{tabular}


Addressing Misconceptions in EFL Literature Learning Using Confidence Weighting Measures: Towards an EFL Literature Concept Inventory

\begin{tabular}{|c|c|c|c|c|c|c|}
\hline & & Strongly Disagree & Disagree & Neutral & Agree & Strongly Agree \\
\hline 3 & $\begin{array}{l}\text {...helped me understand } \\
\text { how I can improve }\end{array}$ & 1 & 2 & 3 & 4 & 5 \\
\hline & \multicolumn{6}{|c|}{ Answering questions in this format was... } \\
\hline 4 & ...difficult & 1 & 2 & 3 & 4 & 5 \\
\hline 5 & ...fun & 1 & 2 & 3 & 4 & 5 \\
\hline 6 & ...confusing & 1 & 2 & 3 & 4 & 5 \\
\hline \multirow[t]{2}{*}{7} & ...confidence-building & 1 & 2 & 3 & 4 & 5 \\
\hline & \multicolumn{6}{|l|}{ Normally,... } \\
\hline 8 & $\begin{array}{l}\text { I reflect on what I am } \\
\text { learning. }\end{array}$ & 1 & 2 & 3 & 4 & 5 \\
\hline 9 & I organize my learning well. & 1 & 2 & 3 & 4 & 5 \\
\hline 10 & \begin{tabular}{|lll} 
I review my learning \\
regularly.
\end{tabular} & 1 & 2 & 3 & 4 & 5 \\
\hline 11 & I do not take many risks. & 1 & 2 & 3 & 4 & 5 \\
\hline
\end{tabular}

\section{AUTHOR'S BIOGRAPHY}

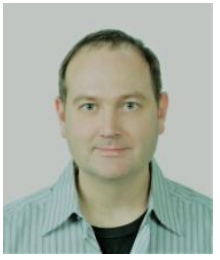

Jackson Ver Steeg, Jr. is an Iowa boy who has been living and teaching for 15 years in the Department of English and the Center for English Language Teaching at Wenzao Ursuline University of Languages in Kaohsiung, Taiwan. His current research interests include education for sustainable development, metacognition and motivational factors in the EFL classroom, and children's literature. In his spare time, he enjoys watching baseball, cricket, and soccer, trying to grow tomatoes on his tiny balcony, and fishing.

Citation: Jackson Ver Steeg, Jr. "Addressing Misconceptions in EFL Literature Learning Using Confidence Weighting Measures: Towards an EFL Literature Concept Inventory " International Journal on Studies in English Language and Literature (IJSELL), vol 6, no. 12, 2018, pp. 13-23. doi: http://dx.doi.org /10.20431/2347 3134.0612002 .

Copyright: (C) 2018 Authors. This is an open-access article distributed under the terms of the Creative Commons Attribution License, which permits unrestricted use, distribution, and reproduction in any medium, provided the original author and source are credited. 